\title{
Epidemiological estimates of Respiratory diseases in the hospital population, Faisalabad, Pakistan.
}

\author{
Tayyaba Sultana $^{1}$; ; Aqsa Afzal1; Salma Sultana ${ }^{1}$; Khalid Al-Ghanim²; Tehniat Shahid ${ }^{3}$; \\ Zahra Jabeen ${ }^{4}$; Nusrat Turab ${ }^{4}$; Z. Ahmed ${ }^{2}$; Shahid Mahboob ${ }^{2,1^{*}}$. \\ ${ }^{1}$ Department of Zoology, Government College University Faisalabad, Faisalabad, Pakistan; ${ }^{2}$ King Saud University, \\ Riyadh, Saudi Arabia; ${ }^{3}$ Department of Physical Therapy, University of Faisalabad, Pakistan; ${ }^{4}$ Hollywood Avenue \\ Somerset NJ08872, USA
}

\begin{abstract}
A cross sectional study was conducted in two types of respiratory patients in hospital population. It was found that tuberculosis (T.B) was the most common type (29.66\%) followed by the asthma (28.08\%) and chronic obstructive pulmonary disease (COPD) (11.31\%). Average age of diagnosis was $42.15 \pm 0.65$ years and average age at present $47.99 \pm 0.70$ years. Age group 51-60 years was more prone to this disease (21.13\%). Most of the patients were married (80.06\%). The highest representation of patients with respiratory diseases was observed in $1^{\text {st }}$ birth order $(30.36 \%)$ followed by $2^{\text {nd }}(26.49 \%)$ and $3^{\text {rd }}(18.45 \%)$, while the lowest was in $10^{\text {th }}$ birth order $(0.40 \%)$. Tuberculosis, asthma and COPD are the most prevalent types of respiratory diseases. Respiratory diseases were more common in males, in first birth order and in people of age group 51-60 years. This disease was more common in married, unemployed, less educated, and lower socioeconomic status people. Socioeconomic status and urban and rural living had a profound effect on the onset of disease.
\end{abstract}

Key Words: Respiratory, age, sex, urban, rural, income

*Author for correspondence: 


\section{INTRODUCTION}

Respiratory System is crucial for every human being, without it, life would cease, so for sustaining the life. Respiratory disease is the term used for infections of the respiratory system affecting lungs, pleural cavity, bronchial tubes, trachea, upper respiratory tract, and of the nerves and muscles used in breathing either individually or in combinations [1]. Respiratory diseases start from a mild condition such as the common cold, to life threatening such as bacterial pneumonia or pulmonary metabolism [2].

In the world, lower respiratory infections are the leading cause of mortality causing almost $12 \%$ of all deaths. Lower respiratory infections killed 3.8 million people, with 2.6 million deaths in the non-industrialized regions [3]. According to [4] over 1 billion people have suffered from chronic respiratory diseases worldwide, around 300 million suffered from asthma, 210 million from chronic obstructive pulmonary disease (COPD). In the US, one billion people suffer from colds every year and similarly, some form of chronic lung disease, most commonly COPD and asthma [2] affects one in seven people in the UK. According to [3] it is estimated that the number of deaths in developing countries are about 2643000 (lower respiratory diseases), 1021000 (Tuberculosis) and 748000 (COPD) individuals while in developed countries it is about 1,180,000 and 571000 and 1829000 deaths, respectively. The big five respiratory syndromes (COPD, asthma, lung cancer, pneumonia and tuberculosis, have accounted for $20 \%$ of mortality worldwide [5-6]. According to [7] ranking in Pakistan about $14.60 \%$ people die due to Influenza \& Pneumonia, about $5.56 \%$ due to tuberculosis, about $4.75 \%$ due to lung diseases while about $0.51 \%$ dies due to asthma.

Tuberculosis (TB) is an infectious disease of worldwide significance that kills more people on a global scale than any other infectious disease. About $32 \%$ of the world's population are infected with TB [8]. In certain, the one of global leading causes of morbidity and mortality is TB. According to the WHO, which collects yearly country outlines of reported TB cases, TB affected 2.4 million in 2001. About 300 million people were suffering from asthma in all over the world compared with 5 out of every 100 persons in Pakistan [9]. The major bases of asthma are environmental changes, pollution and substandard life styles. Asthma occurrence had increased by $38 \%$, in equivalent to a similar increase in asthma-like signs and allergic rhinitis during the past 20 years [10]. Chronic obstructive pulmonary disease (COPD) is a term that refers to a large group of lung diseases characterized by obstruction of airflow that interferes with normal breathing. Emphysema and chronic bronchitis are the most important conditions that compose COPD and they frequently coexist. [11] reported COPD as a leading cause of worldwide mortality and disability. COPD has affected 210 million people in the world and 44 million people in Europe [6]. Presently, it is the fourth leading cause of death and will become the third leading cause of death by 2030 [12]. There are many risk factors (tobacco, childhood pneumonia, various occupational exposures, and air pollution) associated with the development of COPD and that are more prevalent in developing countries compared to developed countries, (Center for strategic \& international studies [13].

Respiratory diseases frequently occurred in smokers, rural resident, elderly patients, in peoples with lower body mass index (BMI), with childhood pulmonary problems, with inherited pulmonary diseases and due to poor kitchen ventilation, exposure to occupational dust or biomass fuels [14]. Outdoor air pollution also causes severe respiratory diseases [11]. Outdoor air pollution is also one of the risk factor for causing severe respiratory diseases and a major issue in Pakistan, particularly in the crowded city areas where air pollution levels are known to have crossed safe limits, 
Respiratory diseases in hospital population

whereas in others, they have reached threshold limits (Environmental protection agencies [15].

Smoking scenario is pathetic in terms of its effects and revenue involved. [6] anticipated that $36 \%$ of adult Pakistani males and $9 \%$ of females are involved in daily smoking. Pakistan is no exception and there is rapid increase in respiratory diseases. The worldwide increase in the prevalence of respiratory diseases is posing a massive health problem. Although numerous studies have been documented the worldwide increase in respiratory diseases, but with specific geographical limitations. The prevalence of respiratory diseases in Pakistan has been increasing for the last few decades, but data on the current estimate of population incidence, prevalence of respiratory diseases in Pakistan in not updated and not well documented especially from the epidemiological and genetical point of view. This epidemiological work was aimed to study the epidemiology of respiratory diseases, its occurrence, prevalence, and allied risk factors in a hospital population of Faisalabad city to collect a baseline information on different types of respiratory diseases prevailing in the current population. The information generated would be submitted to policy makers in their future planning of healthcare policies and in adopting preventive measures.

\section{MATERIALS AND METHODS}

A cross sectional study was carried out at Allied and District Head Quarter Hospitals, Faisalabad, Pakistan in July 5, 2013 to January 4, 2014. These hospitals were visited for data collection of data by interviewing the respiratory patients or their close relatives, using questionnaire data sheet (specimen attached). The collected data include the information regarding diagnosis that is a specific type of respiratory disease diagnosed by specialist/prescription, surname, sex, present age, age at diagnosis, marital status, the exact relationship between father and mother, the exact relationship between husband and wife (if married) and birth order of the patient and so forth. The information regarding lifestyle (including smoking status, diet) area (urban or rural), type of a residential location (industrial or non-industrial), disease symptoms (cough, phlegm, episode of cough and phlegm, wheezing, breathlessness), pneumonia, hay fever, emphysema, asthma and any other chest illness. Information about educational status, socio-economic status (on the basis of occupation) and occupation was also collected pointing out dust or chemical exposure at their work places. Occupations are grouped into the following categories (I to VII) [16].

I. Professional and managerial

II. Intermediates

III.Skilled non manual

IV. $\quad$ Skilled manual

V. Partially skilled

VI. Unskilled

VII. Retired or jobless

Pedigree extending to a minimum three generations was also attempted to draw if the patient could recall correctly about the disease in their family. Mode of inheritance of respiratory disease was predicted through pedigree analysis. The data were analyzed in two ways. Firstly, the sample was analyzed as a whole to get information about the hospital population. Secondly, the sample was analyzed for the study of consanguinity. Parental genetic relation in marriages was classified into first cousins (FC), second cousins (SC), distant relatives (DR), ethnic group and unrelated. Statistical Analysis: 
The statistical analysis was carried out including percentages, mean, standard error, chi-square test. Mean coefficient of inbreeding was also calculated by following [17] formula which is as follows:

$\mathrm{F}=\frac{\mathrm{IC} \times 0.0625}{\text { Total number of each type }}+\frac{\mathrm{I} \frac{1}{2} \mathrm{C} \times 0.031}{\text { Total number of each type }}+$
$\begin{aligned} & \text { Total number of each type } \\ & \text { type }\end{aligned}$

\section{RESULTS}

\subsection{General population study}

The present study was carried out on 1008 subjects affected by respiratory problems, out of which 594 were male and 414 were female. Overall, 16 types of respiratory diseases were observed in these patients. Tuberculosis were observed as the most common type $(29.66 \%)$ followed by asthma $(28.08 \%)$ and chronic obstructive pulmonary Disease (COPD) (11.31\%) (Table 1 and Fig. 1). Males (58.9\%) patient suffered more with the respiratory diseases compared to females. A highly significant difference between male and female respiratory patients $\left(\mathrm{x}^{2} 32.14 ; \mathrm{P}<\right.$ 0.001). It has been observed the males were more affected for the most of the respiratory disease, pneumonia, tuberculosis and significant differences in case of asthma and chest infection and non-significant differences $(\mathrm{P}>0.05)$ in tonsillitis in comparison to females. Female patients were suffering more with bronchitis and lung collapse compared to males. According to the available data, the male and female patients were categorized into nine age groups ranged as $1-10$ to $80^{+}$. The maximum number of respiratory patients $(21.13 \%)$ were observed in the age group of 51- 60 years, followed by 41-50 years (17.66 \%) and 61-70 years (14.19\%), respectively, and minimum patients (3.08\%) in the age group of 1-10 years (Fig. 1). Maximum number of male patients was belonged to age group 51- 60 years (21.89 $\%)$ followed by $41-50(17.17 \%)$ and $61-70$ years $(13.64 \%)$ whereas the minimum number of male patients was observed in the age group of $1-10$ years $(2.53 \%)$. In case of females, maximum patients were belonged to age group 51-60 (20.05\%) followed by $41-50$ years $(18.36 \%)$ and $61-70$ years $(14.98 \%)$ while minimum female patients $(3.14 \%)$ were in the age group of $80^{+}$years (Table 1). As tuberculosis are more prevalent disease is significantly more prevalent in male $(59.87 \%)$ than in females $(40.13 \%)(\mathrm{P}<0.001)$ and sex ratio/100 females were $100 \%$ : $149.17 \hat{\jmath}$.

Overall, $80.06 \%$ of respiratory patients were married and $19.94 \%$ were unmarried. Birth order distribution of 1008 respiratory patients consisting of 594 males and 414 females was done into 10 birth orders for each type of respiratory problem (Table 2). The highest representation of patients was observed in first three birth orders 30.36 $\%, 26.49 \%$ and $18.45 \%$, respectively, and it was lowest- $0.40 \%$ in the 10th birth order. Education of patient had a highly significant effect $(\mathrm{P}<0.001)$ on the affliction of disease. It was observed that patients with nil education $(24.80 \%)$ and school level education $(61.61 \%)$ suffered more from respiratory than those who had attained education at the college / university level (13.59 \%). The highest percentage distribution of respiratory patients was observed in retired / jobless category (42.46\%) followed by skilled non-manual category (21.83\%). The lowest percentage distribution in respiratory patients was observed in unskilled (1.59\%) (Fig. 2). The socioeconomic status of the respiratory patients (based on their occupation) showed a highly significant effect $(\mathrm{P}<0.001)$ of affliction of disease. Patients with lower socioeconomic status, $54.27 \%$ suffered more from respiratory disease followed by middle class $39.88 \%$ and minimum in upper class $5.85 \%$. Respiratory patients were prevalent in all birth orders birth order (1-10). 
Respiratory diseases in hospital population

Table 1. Percentage distributions of males and females among respiratory diseases and sex ratio / 100 females.

\begin{tabular}{|c|c|c|c|c|c|c|c|}
\hline \multirow{2}{*}{ Sr. No. } & \multirow{2}{*}{$\begin{array}{c}\text { Types of } \\
\text { respiratory disorder }\end{array}$} & \multicolumn{2}{|c|}{ Male } & \multicolumn{2}{|c|}{ Female } & \multirow{2}{*}{$\begin{array}{c}\text { Sexes } \\
\text { combined }\end{array}$} & \multirow{2}{*}{$\begin{array}{l}\text { Sex ratio/100 } \\
\text { females }\end{array}$} \\
\hline & & No. & $\%$ & No. & $\%$ & & \\
\hline 1 & Tuberculosis & 179 & $59.87 \%$ & 120 & $40.13 \%$ & 299 & 149.17 \\
\hline 2 & Asthma & 162 & $57.24 \%$ & 121 & $42.76 \%$ & 283 & 133.88 \\
\hline 3 & COPD & 59 & $51.75 \%$ & 55 & $48.25 \%$ & 114 & 107.27 \\
\hline 4 & pneumonia & 49 & $76.56 \%$ & 15 & $23.44 \%$ & 64 & 326.67 \\
\hline 5 & Cough & 37 & $61.67 \%$ & 23 & $38.33 \%$ & 60 & 160.87 \\
\hline 6 & whooping cough & 29 & $64.44 \%$ & 16 & $35.56 \%$ & 45 & 181.25 \\
\hline 7 & bronchitis & 12 & $38.71 \%$ & 19 & $61.29 \%$ & 31 & 63.16 \\
\hline 8 & chest infection & 16 & $69.57 \%$ & 7 & $30.43 \%$ & 23 & 228.57 \\
\hline 9 & pharyngitis & 9 & $47.37 \%$ & 10 & $52.63 \%$ & 19 & 90.00 \\
\hline 10 & influenza & 10 & $71.43 \%$ & 4 & $28.57 \%$ & 14 & 250.00 \\
\hline 11 & lung collapse & 5 & $38.46 \%$ & 8 & $61.54 \%$ & 13 & 62.50 \\
\hline 13 & septicemia & 6 & $60.00 \%$ & 4 & $40.00 \%$ & 10 & 150.00 \\
\hline 12 & sarcoidosis & 5 & $50.00 \%$ & 5 & $50.00 \%$ & 10 & 100.00 \\
\hline 14 & pulmonary problem & 6 & $66.67 \%$ & 3 & $33.33 \%$ & 9 & 200.00 \\
\hline 15 & lung infection & 5 & $62.50 \%$ & 3 & $37.50 \%$ & 8 & 166.67 \\
\hline \multirow[t]{2}{*}{16} & tonsillitis & 5 & $83.33 \%$ & 1 & $16.67 \%$ & 6 & 500.00 \\
\hline & Total & 594 & $58.93 \%$ & 414 & $41.07 \%$ & 1008 & 143.48 \\
\hline
\end{tabular}

$\left(\chi^{2}=32.14 ; \mathrm{P}<0.001\right)$

Table 2: Percentage distribution of married and unmarried respiratory patients.

\begin{tabular}{|c|c|c|c|c|c|c|c|c|}
\hline \multirow{2}{*}{$\begin{array}{l}\text { Sr. } \\
\text { No. }\end{array}$} & \multirow{2}{*}{$\begin{array}{l}\text { Marital } \\
\text { Status }\end{array}$} & \multicolumn{2}{|c|}{ Male patient } & \multicolumn{2}{|c|}{ Female patient } & \multicolumn{2}{|c|}{ sexes combined } & \multirow{2}{*}{$\begin{array}{c}\text { Sex ratio/100 } \\
\text { females }\end{array}$} \\
\hline & & No. & $\%$ & No. & $\%$ & No. & $\%$ & \\
\hline 1 & Married & 486 & 81.82 & 321 & 77.54 & 807 & 80.06 & 151.40 \\
\hline 2 & Unmarried & 108 & 18.18 & 93 & 22.46 & 201 & 19.94 & 116.13 \\
\hline & Total & 594 & 100 & 414 & 100 & 1008 & 100 & 143.48 \\
\hline
\end{tabular}




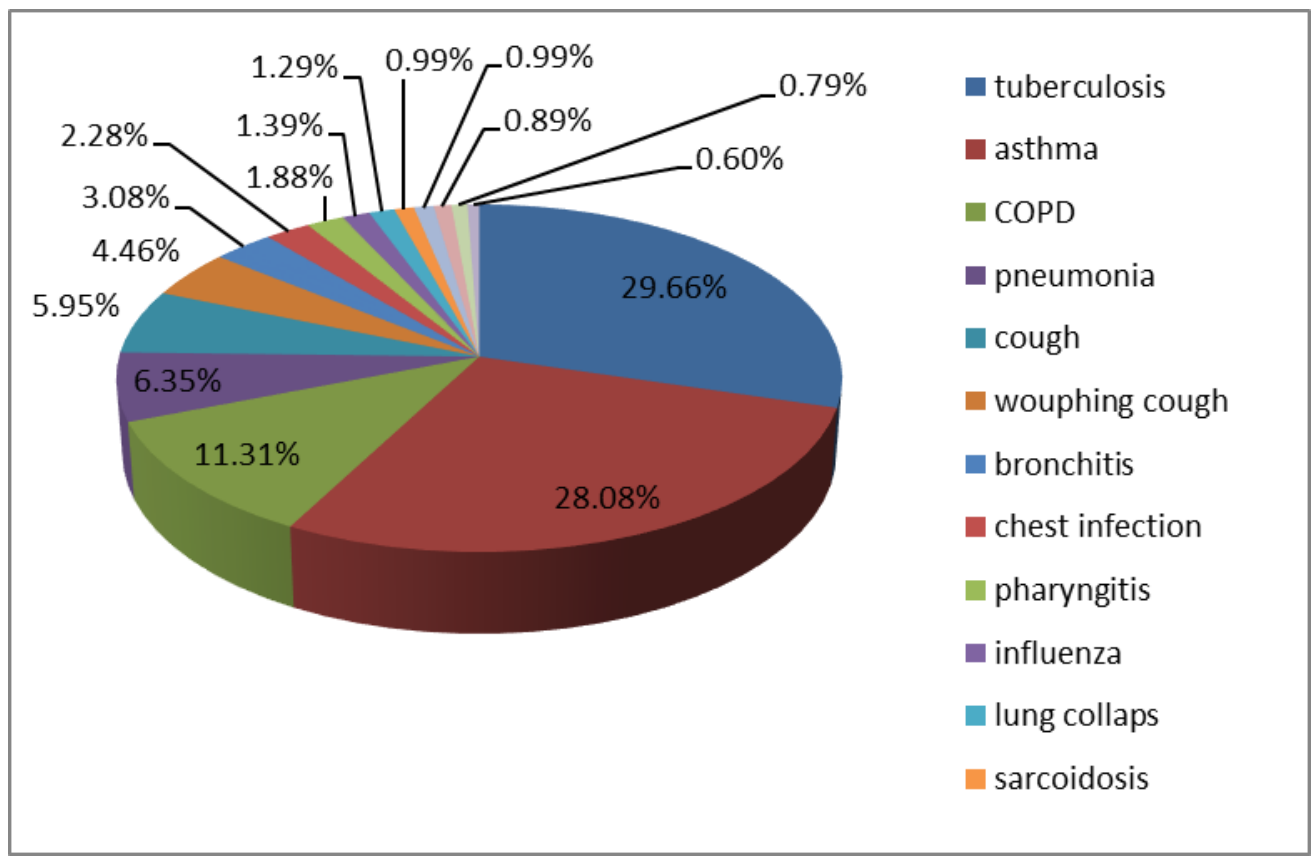

Figure 1. Prevalence of percentage distribution of different types of respiratory diseases in hospital population in Faisalabad, Pakistan.

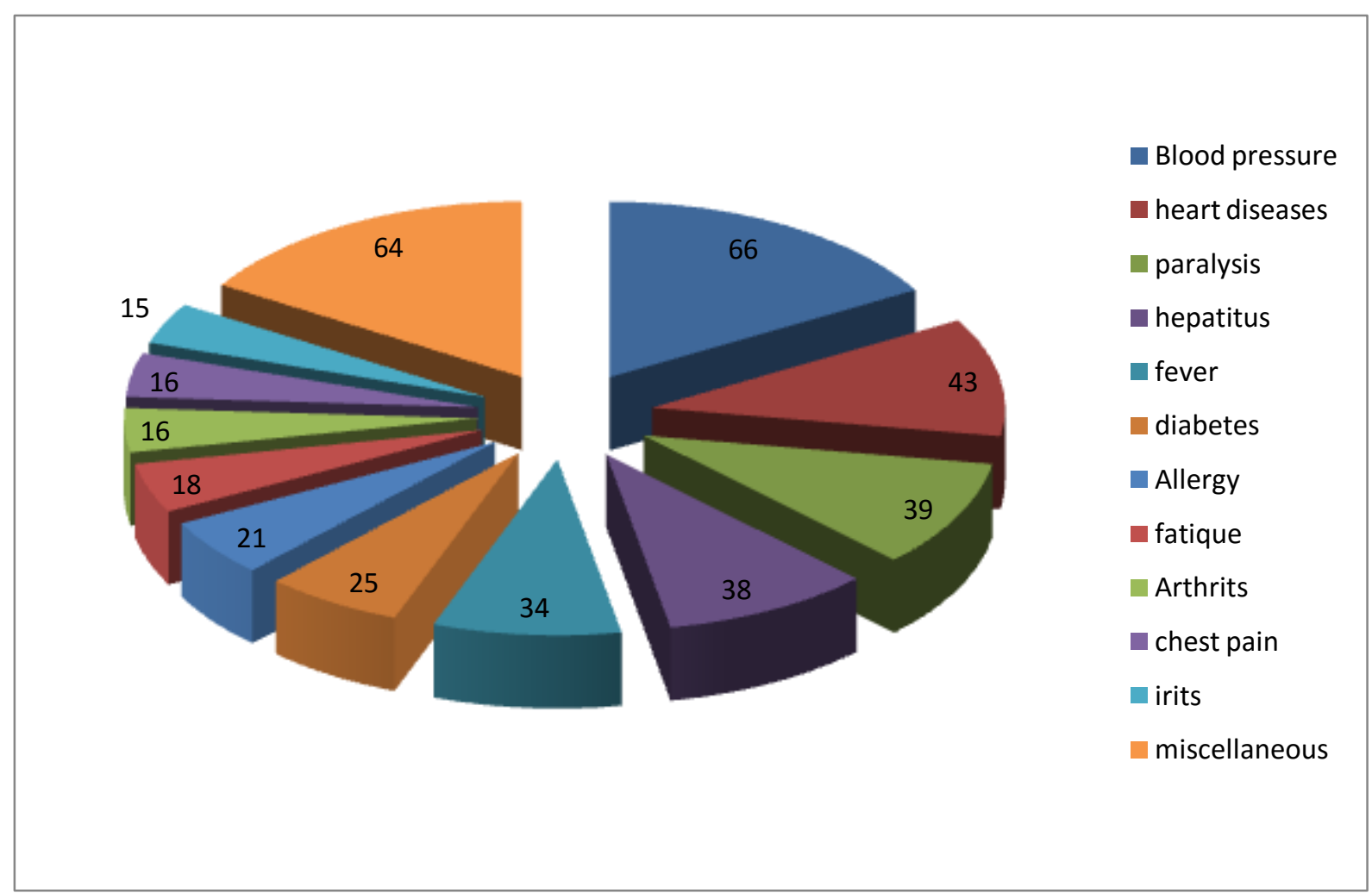

Figure 2: Percentage distribution of different associated diseases in respiratory patients in hospital population in Faisalabad, Pakistan.

3.2 Consanguinity and respiratory diseases:

The percentage distribution of respiratory patients according to their parental genetic relationships was observed. The main identified relationships between parents of 
patients were first cousin (1C), first cousin once removed $\left(1 \frac{1 / 2 C}{2}\right)$, second cousin (2C), distant relations (DR), caste (B) and unrelated spouses (U). Maximum percentage was found in offspring of First cousin (29.46\%), followed by caste relative $(28.17 \%)$ and a second cousin $(22.42 \%)$ and least percentage $(0.89 \%)$ was found in the offspring of first cousin once removed $\left(1 \frac{1}{2} \mathrm{C}\right)$.

3.3 Lifestyle and respiratory disease

\subsubsection{Smoking and non-smoking}

The information regarding smoking was also observed in the case of respiratory patients. Details of smoking status in respiratory patients revealed that there were smokers $(37.60 \%)$, passive smokers $(22.72 \%)$, ex-smokers $(4.76 \%)$ and nonsmokers $(34.92 \%)$. The difference between the four groups was highly significant $(\mathrm{P}<0.001)$. Out of 594 male patients, there were smokers $(50.34 \%)$, passive smokers $(12.63 \%)$, ex-smokers $(5.05 \%)$, and non-smokers $(31.99 \%)$. While out of 414 female patients, there were smokers $(19.32 \%)$, passive smokers $(36.96 \%)$, exsmokers (4.59\%) and nonsmokers (39.13\%) (Table 3). The difference between smokers, nonsmokers, passive-smokers and ex-smokers were highly significant $(\mathrm{P}<0.001)$.

Table 3: Percentage distribution of male and female respiratory patients according to their smoking status.

\begin{tabular}{|c|c|c|c|c|c|}
\hline Sr. No. & Smoking status & $\begin{array}{c}\text { No. of male } \\
\text { patients }\end{array}$ & Percentage & No. of female patients & Percentage \\
\hline 1 & Smoker & 299 & $50.34 \%$ & 80 & $19.32 \%$ \\
\hline 2 & Passive-smoker & 75 & $12.63 \%$ & 153 & $36.96 \%$ \\
\hline 3 & Ex-smoker & 30 & $5.05 \%$ & 19 & $4.59 \%$ \\
\hline 4 & Non-smoker & 190 & $31.99 \%$ & 162 & $39.13 \%$ \\
\hline & Total & 594 & $100.00 \%$ & 414 & $100.00 \%$ \\
\hline
\end{tabular}

\subsubsection{Diet}

In case of diet status, respiratory patients preferred to have a mixed diet $(66.77 \%)$ followed by a vegetarian (28.27\%) and non-vegetarian $(4.96 \%)$ and $51.98 \%$ respiratory patients showed severe malnutrition followed by a moderate $37.20 \%$ and mild $10.81 \%$ malnutrition (Fig. 2).

\subsubsection{Indoor and out-door pollution}

According to the occupational status of respiratory patients, $51.88 \%$ were facing indoor air pollution. Whereas $47.12 \%$ were facing out-door pollution. It has been observed $31.15 \%$ of respiratory patients were exposed to dust and $12.59 \%$ to various chemicals. 3.3.4 Origin: distribution of respiratory patients in urban and rural population

Out of 1008 scored patients, there were $60.91 \%$ rural and 39.09\% urban respiratory patients. The difference between rural and urban population of respiratory patients was highly significant $(\mathrm{P}<0.001)$. Residential location of 1008 patients was recorded, $84.52 \%$ were living in non-industrial, $11.21 \%$ in industry and $4.27 \%$ in semi-industrial areas (Fig. 2). The difference between urban and rural patients was highly significant $(\mathrm{P}<0.001)$. The findings of this study are lined with the results of [31].

\section{4 Disease in the family}


In three top leading cases where the majority of patients involved, Tuberculosis, Asthma and COPD families were traced back. Out of 1008 subjects, there were 278 subjects $(27.58 \%)$ involving risk families. Among these affected patients, 146 subjects $(52.52 \%)$ were male, while 132 subjects (47.48\%) female. Relations of 847 affected relatives included a paternal grandfather, paternal grandmother, maternal grandfather, maternal grandmother, father, mother, brother, sister, son, daughter, paternal cousin, maternal cousin, paternal uncle, paternal aunt, maternal uncle, maternal aunt and in-laws comprising of $47.70 \%, 40.73 \%$ and $11.57 \%$ affected relatives of asthma, tuberculosis and COPD patients, respectively.

3.5 Chronic symptoms among top leading respiratory diseases

In case of three top leading respiratory diseases, some symptoms associated with the severity of respiratory types was also observed. In case of T.B, asthma and COPD almost $(58.86 \%, 48.06 \%$, and $51.75 \%$, respectively) coughed $4-6$ times a day at the time of survey among which $25.42 \%$ (T.B), 39.47\% (asthma) and $20.14 \%$ (COPD) met the criteria of having chronic cough. $46.15 \%$ (T.B), 13.07 (asthma) and 18.42\% (COPD) patients' expectorated phlegm at least twice a day at the time of the survey. Among them, 21.93\% (T.B), 4.59\% (asthma) and 31.44\% (COPD) patients met the criteria of having chronic phlegm. 89.47\% (T.B), 47.35\% (Asthma) and 68.23\% (COPD) patients were observed experiencing wheeze (Table 1).

3.6 Associated diseases

Prevalence of 27 associated diseases in 395 (39.19\%) to leading cases of respiratory patients (Figure 2). The most prevalent disease was blood pressure (16.71\%) followed by heart diseases $(10.89 \%)$, paralysis $(9.87 \%)$, hepatitis $(9.62 \%)$ and fever $(8.61 \%)$. Least percentage was found in thyroid, leucorrhea and cancer patients $(0.25 \%$, each). Among male patients, maximum percentage was in the patients of blood pressure (19.46\%) and minimum percentage was in the patients of mental problem, goiter and pneumonia $(0.45 \%)$ each (Fig. 3). Among female respiratory patients, maximum percentage was in the patients of blood pressure (13.22\%) and minimum percentage was of thyroid, leucorrhea and cancer $(0.57 \%)$ each.

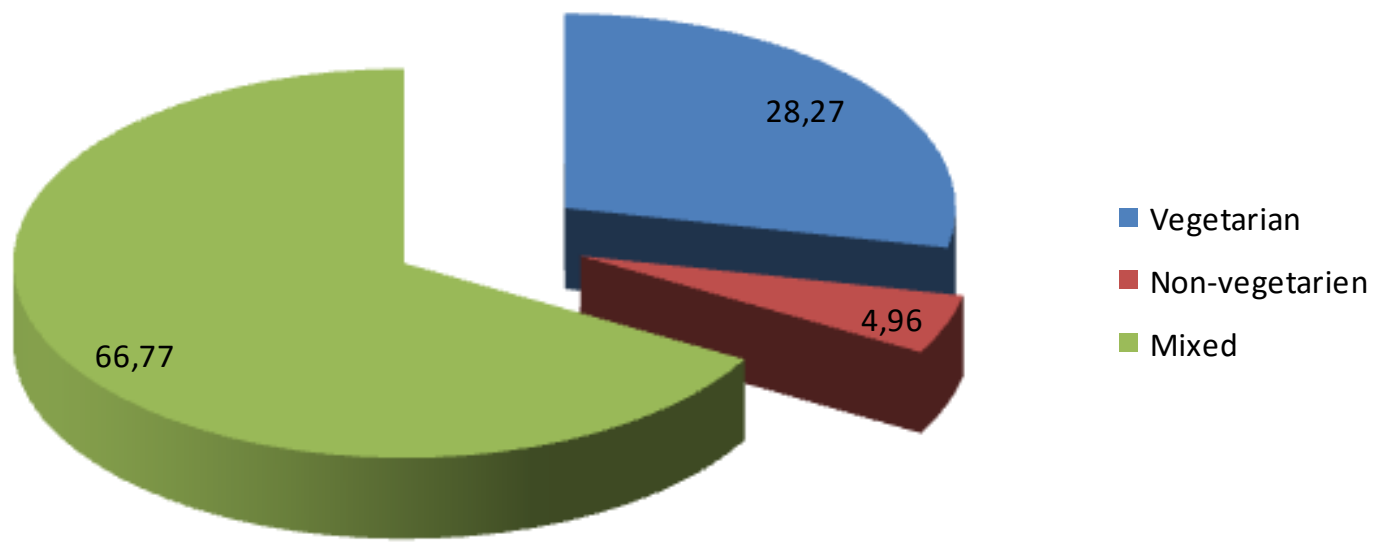


Respiratory diseases in hospital population

Figure. 3: Percentage distribution of respiratory patients according to their diet status.

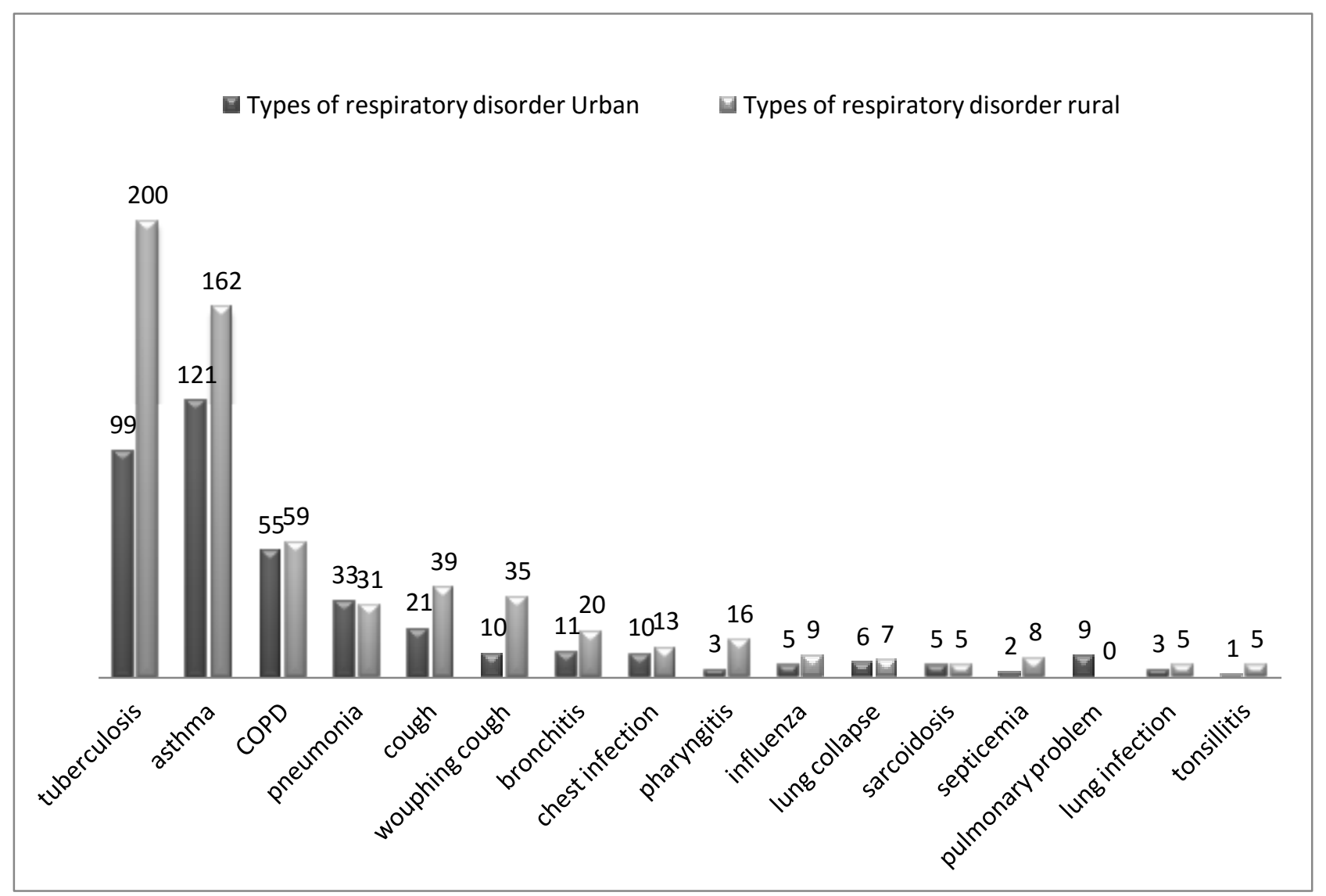

Figure 4: Comparison of different type of respiratory diseases in urban and rural population.

\section{DISCUSSION}

The findings of this study was comparable to [18]. They reported asthma, COPD, pneumonia, lung cancer and tuberculosis (TB) to be most common among hospitalized patients. The above findings are also in line with [19] findings they reported that hundreds of millions of people of all ages suffer from chronic respiratory diseases which include asthma and respiratory allergies, COPD, occupational lung diseases and pulmonary hypertension. [20] also reported Tuberculosis as a disease of poor countries like Pakistan and similar results obtained in this report. [21] also reported an increased in the prevalence of and mortality from COPD and asthma in the industrialized world. [9] reported that from all over the world about 300 million people were asthmatic, while out of every 100 persons 5 were asthmatic in Pakistan and these findings supporting the present study in this regard. In the present study, 58.93\% males and $41.07 \%$, females were affected. Males were more liable to respiratory diseases than women were. The present finding agrees with [20] findings who reported more affliction of males towards respiratory diseases. [22] also reported that respiratory symptoms are in higher percent.

The prevalence of tuberculosis noted in present study agreed with the result of [19] who reported that more male than females are affected with tuberculosis. [11] ranked Pakistan at $8^{\text {th }}$ position among 22 high TB risk countries. Asthma is the $2^{\text {nd }}$ leading type of respiratory diseases in the present study significantly more prevalent in males 
$(57.24 \%)$ than in females $(42.76 \%)(\mathrm{P}<0.001)$ and sex ratio/100 females were 100 : $133.88{ }^{7}$. These findings are in contrast with findings of [18] who find that asthma was higher among females (63.3\%) than males (36.7\%); [23], who reported that the prevalence of asthma was higher in females $(65.0 \%)$ than in males $(35.0 \%)$. This disagreement is due to the asthmatic patients in this study were laborer and smoker, the malnutrition, working environment and low quality tobacco could be one of the reasons. COPD $(11.31 \%)$, the third leading respiratory diseases were prevalent in both males $(51.75 \%)$ and $(48.25 \%)$ females and sex ratio/100 females were 100 \%: 107.27 $\lambda$. These findings are in accordance with the finding of [24], as they reported overall prevalence in chronic obstructive lung disease was equal in men and women. The prevalence of COPD in the present study is supported by a report of [6] showing that COPD affects 210 million people in the world and 44 million people in Europe. [25] reported that low socioeconomic status was linked to reduced lung function in adults. [26] demonstrated that low socioeconomic status seems to be related to the high incidence of respiratory diseases, but very little is known in high socioeconomic classes. These findings are in agreement with the findings of the present study. According to WHO (2008) reported that 36\% of adult Pakistani males, and 9\% of females, smoke. [27] reported within only a few years of smoking beginning severe respiratory effects of smoking and these findings related to the above findings.

Our results are in line with [28] findings, who estimated the frequency of chronic respiratory diseases (CRD) and frequent acute respiratory signs (FARS) were associated with the level of outdoor air pollution in the local environment (low, moderate and high pollution areas). [29] reported that occupational exposure to dust, fumes or gases, especially among never-smokers, increased the mortality from COPD. [30] also reported that the pattern of pulmonary function, obstruction was shown to be reasonable to the period of exposure to dust caused by sweeping and supporting the present findings. [32] reported that the most common signs were nocturnal cough $(31.5 \%)$, while wheezing and nasal allergies were almost equal (17.8\% and $18.2 \%$ ) whereas stiffness of the chest and shortness of breath was recognized in $13.2 \%$ and $10.74 \%$ subjects, respectively. The findings for associated diseases were in accordance with the findings of [33], who reported most commonly associated diseases were cardiac (17.4\%), hypertension (16.77\%) and arthritis $(18.0 \%)$. [34] investigated that childhood asthma intensely linked to a family history of asthma and allergic rhinitis and maternal breast milk and parents smoking history is a key factor for incidence of asthma from the habitation of urban place. [35] also reported some risk factors such as abnormal liver function test, low albumin and occurrence of cardiomegaly; respiratory rate and blood pressure and weather on admission high blood urea were more significant death risk factors than age. [18] findings are also in line with the present study, who reported most prevalent associated diseases observed were diabetes mellitus $22.8 \%$ and hypertension $15.1 \%$, while cardiovascular conditions, for instance ischemic heart disease and congestive heart failure account for a good share (20.7\%) as an associated disorder.

\section{CONCLUSION}

Tuberculosis, Asthma and COPD are the most prevalent types of respiratory diseases. Respiratory diseases were more common in males, in first birth order and in people of age group 51-60 years. This disease was more common in married, unemployment, less educated, and lower socioeconomic status people. Socioeconomic status and urban and rural living had a profound effect on the onset of disease. 
Respiratory diseases in hospital population

\section{ACKNOWLEDGEMENTS}

The authors would like to express their sincere appreciation to the Deanship of Scientific Research at King Saud University for its funding of this research through the Research Group Project No. Prolific Research Group No. 1436-011.

\section{REFERENCES}

[1] Divita L. List of diseases of the respiratory system. Retrieved august, 15, 2013 from http: //www.livestrong.com/article/79558-list-diseases-respiratory-system/. 2011

[2] Khan A, Salik S. Increasing air pollution causing respiratory diseases in Pakistan. Retrieved July 25, 2012, from http://www. dailytimes.com.pk /default. asp? page=story _2-32009_pg14_1.2009.

[3] World Health Organization. World health Statistics, 2002. Death and daly estimates by cause. Retrieved January 13, 2008, from http:// www. who.int/ entity/ healthinfo /statis tics/bodgbddeathdalyestimates. $x$ ls. 2002.

[4] World Health Organization. Global Burden of Disease Estimates. Available at http://www.who.int/healthinfo/statistics/bodgbddeathdalyestimates.xls (accessed 30 January, 2008). 2007.

[5] Loddenkemper R, Gibson GJ, Sibille Y. The First Comprehensive Survey on Respiratory Health in Europe. European Lung White (pp. 16-23). Sheffield: European Respiratory Society/European Lung Foundation. 2003.

[6] World Health Organization. World health statistics. Geneva .Retrieved March 23, 2010, from http://www.who.int/whosis/ whostat/EN_WHS08__Full.pdf . 2008.

[7] World Health Organization. World Health Statistics. Online database. Geneva: World Health Organization. Retrieved June 6, 2011, from www. who.int/ whosis/ whostat /EN_WHS2011_Full.pdf. 2011.

[8] Dye C, Scheele S, Dolin P, Pathania V, Raviglione MC. Global Burden of Tuberculosis: Estimated Incidence, Prevalence and Mortality by Country. J Amer Med Asso. 1999; 28: $677-686$.

[9] Murtaza G, Qureshi A, Akmal N, Haroone S. Asthma: Etiologies, diagnosis and prevention. $J$ Pharm Cosm Sci. 2013; 1(2): 19-23.

[10] De Marco R, Cappa V, Accordini S, Rava M, Antonicelli L, Bortolami O, Braggion M, Bugiani M, Casali L, Cazzoletti L, Cerveri I, Fois AG, Girardi P, Locatelli F, Marcon A, Marinoni A, Panico MG, Pirina P, Villani S, Zanolin ME, Verlato GG. Trends in the prevalence of asthma and allergic rhinitis in Italy between 1991 and 2010. Europ Resp J. 2012; 39(4): 883-892.

[11] Anto JM, Vermeire P, Vestbo J, Sunyer J. Epidemiology of chronic obstructive pulmonary disease. Europ Resp J. 2001; 17, 982-994.

[12] Jemal A, Ward E, Hao Y, Thun M. Trends in the leading causes of death in the United States, 1970-2002. JAMA, 2005; 294: 1255-1259.

[13] CSIS. Chronic diseases and their risk factors-a global burden. Retrieved July 30, 2012, from http://www.smartglobalhealth.org/issues/entry/chronic-diseases. 2012.

[14] Zhong N, Wang C, Yao W, Chen P, Kang J, Huang S, Chen B, Wang C, Ni D, Zhou Y, Liu S, Wang $X$, Wang D, Lu J, Zheng J, Ran P. Prevalence of chronic obstructive pulmonary disease in China. Amer J Resp Criti Care Med. 2007; 176: 753-760.

[15] Environment Protection Agencies Study. Retrieved august, 14, 2013 from http:/ /www. pakepa.org/Article2.asif.html . 2004.

[16] Government of Pakistan. (1988). Population Demographic Survey-1988. Federal Bureau of Statistics Division, Islamabad. 1988.

[17] Wright SP. Adjusted P-values for simultaneous inference. Biometrics 1992; 48: 10051013.

[18] Alamoudi SO. Prevalence of Respiratory Diseases in Hospitalized Patients in Saudi Arabia: A 5 years study 1996-2000. Annal Thorac Med. 2006; 1(2): 76-80. 
[19] Bousquet J, Dahl R, Khaltaev N. Global alliance against chronic respiratory diseases. Europ Resp J. 2007; 29 :233-239.

[20] Ullah S, Shah SH, Rehman A, Kamal A, Begum N, Khan G. Extra pulmonary tuberculosis in Lady Reading Hospital Peshawar, NWFP, Pakistan: survey of biopsy results. J Ayub Med Coll Abbottabad. 2008; 20(2): 43-60.

[21] Tzortzaki EG, Proklou A, Siafakas NM. Asthma in the Elderly: Can We Distinguish It from COPD?. J Allergy. 2011; 1: 1-7.

[22] Mirabelli MC, London SJ, Charles LE, Pompeii LA. Wagenknecht LE. Occupation and three-year incidence of respiratory symptoms and lung function decline: the ARIC Study. Biomed Central J. 2012; 13:24-32.

[23] Ahmed A, Ahmed F, Raza MZ, Ghani A. Rizvi N. A Descriptive Analysis of Asthma Exacerbations and it's Mortality in Karachi, Pakistan. J Allerg Therap Sci. 2013; 11: 004008.

[24] Schirnhofer L, Lamprecht B, Vollmer WM, Allison MJ, Studnicka M, Jensen RL, Buist AS. COPD prevalence in Salzburg, Austria: results from the Burden of Obstructive Lung Disease (BOLD) study. Chest. 2007; 31: 29-36.

[25] Tabak C, Spijkerman AMW, Verschuren WMM, Smit HA. Does educational level influence lung function decline (Doetinchem Cohort Study)?. Europ Resp J. 2009; 34: 940947.

[26] Prescott E, Godtfredsen N, Vestbo J, Osler M. Social position and mortality from respiratory diseases in males and females. Europ Resp J. 2003; 21: 821-826.

[27] Wennergren G, Ekerljung L, Alm B, Bjerg A, Lotvall J, Lundback B. Alarmingly high prevalence of smoking and symptoms of bronchitis in young women in Sweden: a population-based questionnaire study. Primary Care Resp J. 2013; 22(2): 214-220.

[28] Kukec A, Farkas J, Erzen I, Zaletel-Kragelj L. A prevalence study on outdoor air pollution and respiratory diseases in children in Zasavje, Slovenia, as a lever to trigger evidence-based environmental Health activities. Arch Ind Hyg and Toxicol. 2013; 64: 9-22.

[29] Bergdahl IA, Toren K, Eriksson K, Hedlund U, Nilssonz T, Flodin R, Jarvholm R. Increased mortality in COPD among construction workers exposed to inorganic dust Europ Resp J. 2004; 23:402-406.

[30] Anwar KS, Mehmood N, Nasim N, Khurshid M. Sweeper's lung disease: a crosssectional study of an overlooked illness among sweepers of Pakistan. Int J COPD, 2013; 8:193-197.

[31] Lam HT, Tuong NV, Ekerljung L, Ronmark E, Lundback B. Allergic rhinitis in northern Vietnam: increased risk of urban living according to a large population survey. Clin and Transl Aller. 2011; 1-7

[32] Khan AJ, Hussain H, Omer SB, Chaudry S, Ali S, Khan A, Yasin Z, Imran JK, Mistry R, Baig IY, White F, Moulton LH, Halsey NA. High incidence of childhood pneumonia at high altitudes in Pakistan: a longitudinal cohort study. Bull WHO. 2009; 87(3): 193-199.

[33] Raza MZ, Ahmed A, Ahmed F, Ghani A, Rizvi N. COPD exacerbations: epidemiology and impact on patient's outcome. Int J Env Sci. 23; 3(6): 1899-1908

[34] Majeed R, Rajar UDM, Shaikh N, Majeed F, Arain AA. (Risk Factors Associated with Childhood Asthma. J Coll Phys Surg Pak. 2008; 18 (5): 299-302.

[35] Irfan M, Hussain SF, Mapara K, Memon S, Mogri M, Bana M, Malik A, Khan S, Khan N. A. (2009). Community Acquired Pneumonia: Risk factors associated with mortality in a tertiary care hospitalized patients. J Paki Med Asso. 2009; 59(7): 448-452. 